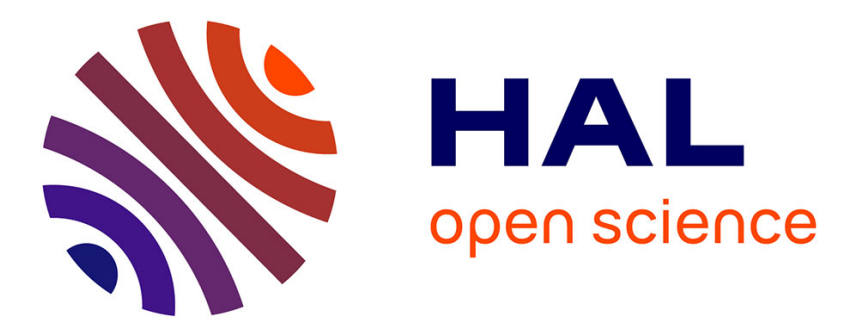

\title{
The Challenge of Making Groundwater Visible: A Review of Communication Approaches and Tools in France
}

\author{
Audrey Richard-Ferroudji, Gaïa Lassaube
}

\section{- To cite this version:}

Audrey Richard-Ferroudji, Gaïa Lassaube. The Challenge of Making Groundwater Visible: A Review of Communication Approaches and Tools in France. Sustainable Groundwater Management A Comparative Analysis of French and Australian Policies and Implications to Other Countries, pp.191-209, 2020, 10.1007/978-3-030-32766-8_10 . hal-02533622

\section{HAL Id: hal-02533622 \\ https://hal.science/hal-02533622}

Submitted on 6 Apr 2020

HAL is a multi-disciplinary open access archive for the deposit and dissemination of scientific research documents, whether they are published or not. The documents may come from teaching and research institutions in France or abroad, or from public or private research centers.
L'archive ouverte pluridisciplinaire HAL, est destinée au dépôt et à la diffusion de documents scientifiques de niveau recherche, publiés ou non, émanant des établissements d'enseignement et de recherche français ou étrangers, des laboratoires publics ou privés. 


\title{
Chapter 10. The Challenge of making ground-water visible: a review of communication approaches and tools in France
}

\author{
Audrey Richard-Ferroudji1 ${ }^{1}$, Gaia Lassaube ${ }^{2}$ \\ ${ }^{1}$ Independent researcher, associated to the French Institute of Pondicherry and \\ UMR G-EAU, Montpellier, France. \\ ${ }^{2}$ Centre Emile Durkheim, Institut Français de Pondichery, Pondichery, India \\ Corresponding author: richardferroudji@gmail.com
}

\begin{abstract}
Groundwater specialists strive to make groundwater issues visible. They face a dual challenge: first to develop knowledge on groundwater and secondly to share this knowledge with other stakeholders who should be included in knowledge development, groundwater management and protection policy. Questioning communication is all the more interesting as groundwater is a quasi-invisible resource. How groundwater and issues can be made more visible? In the field of sociology, with a pragmatist stance, our chapter questions how instruments frame interactions and represent groundwater. Indeed, the groundwater is made visible by tables, indicators, maps, photographs, videos, games, stories in newspaper and spokespersons such as hydrogeologists. Within a project funded by AFB (The French Agency for Biodiversity), we reported on a number of communication approaches and activities implemented in 11 case studies in France. The inventory is based on web mining, grey literature review and interviews. The chapter develops a transversal analysis of the use of the instruments, and identifies assets and limits across the cases according to the following categories: public targeted; content, issues brought to the fore and normative stance adopted; type/format. Finally, concrete recommendations are made.
\end{abstract}

Keywords : Mediation, representation, policy instruments, format, participation, spokespersons 


\section{Exploring the social depth of groundwater and issues of communication}

Over the last fifty years, the development of access to groundwater has increased the pressure on these resources. There is wide recognition today that groundwater overexploitation urgently needs to be curtailed but there is little consensus on how this can be best achieved (Jakeman et al. 2016). In the 1970s and 1980s, groundwater specialists were mainly asked to provide technical support for groundwater prospecting and resource development. Growing concerns over groundwater depletion have challenged the historical mandate of water management institutions. In France, the 1964 Water Act promoted monitoring of groundwater and the 1992 Water Act promoted planning and local management. However, groundwater specialists strive to make groundwater issues visible to policy makers, water users and civil society. They face the challenge of shedding light on groundwater while eyes are focused on surface water. In many situations, there is no shared representation of aquifers (in particular their boundaries as management units) between experts, actors involved in land or water management nor the numerous dispersed users. Hydrogeologists face a dual challenge: first to develop knowledge on groundwater and secondly to share this knowledge with other stakeholders (Baldwin et al. 2012; Van Der Gun 2017) who should be included in knowledge development, groundwater management and protection policy. Meeting this second challenge requires different skills and methods. How should be shared the already available data? How can this knowledge be turned tinto standardized indicators? How can awareness be raised at the local and national level? How can an enabling environment be created for effective communication? Communication is understood here in its broad meaning as the action of making groundwater visible and common with crafting institutions and a body of shared knowledge.

Questioning communication is all the more interesting as groundwater is a quasiinvisible resource. It is mostly hidden from view. It can be seen in broad daylight only when it gushes out from a bore well or when it lies at the bottom of an open well. In contrast to waters flowing in rivers and channels, underground water streams circulate and create hidden interdependencies between human beings and communities. These interdependencies can be shown with maps representing the ground water perimeter at the surface. The quantities stored are materialized in the productions of experts employing instruments: piezometers, satellites images, tables, etc. The groundwater is made visible by photographs, by stories in newspapers or by spokespersons such as hydrogeologists. The users also produce their own representations and instruments. This chapter focuses on objects, artefacts, settings and persons which represent groundwater. Tool is understood here as any means used to communicate.

Within a project funded by AFB (The French Agency for Biodiversity), we reported on a number of communication approaches and activities implemented in 
field projects related to groundwater resources (Richard-Ferroudji et al. 2018) ${ }^{15}$. This chapter reports our findings on the way tools are used to make groundwater visible toward different publics: general public, farmers, elected representatives, etc. Tools were inventoried in 11 case studies in France (See section 2.1.1 and table 10.1). Concrete recommendations are made to improve the same.

This chapter develops a sociological approach to contribute to the exploration of the social depth of groundwater complementary to the physical one. Groundwater practices are indeeddeeply rooted in societies and cultures.Achieving more sustainable management requires a comprehensive understanding of socio-economic, political and institutional structures which is complementary to the technical ones. Such an understanding has significant relevance for better governance of groundwater, which has been of increasing concern since the 90's (Ostrom 1990; Shah 2009; Villholth et al. 2017). There is a need to develop interdisciplinary approaches that integrate the diversity of scientific knowledge on groundwater resources (ranging from hydrogeology to social sciences).However, interdisciplinary projects are still rare (Bouarfa and Kuper 2012)and the social depth of groundwater deserves to be explored on a more systematic basis. There is a growing body of literature that studies the social aspects of groundwater resources but with a broad scope of development (Faysse and Petit 2012; Mitchell et al. 2012; Curtis et al. 2016). Mitchell et al. posit the literature on the topic can be grouped in five broad themes: power and influence, social impact assessment, self-regulation, stakeholder engagement and farmer decision making. Faysse and Petit point that the approaches differ in the content of governance systems recommended to achieve sustainable groundwater use, and especially in the benefits of involving water users in the implementation of governance. Therefore, they also differ on what should be the focus of academic analyses.

In the field of sociology, with a pragmatist stance, our chapter question how tools frame interactions and represent groundwater, considering a plurality of values, interests and attachments to the environment (Thévenot et al. 2000; Richard-Ferroudji and Barreteau 2012). Indeed, groundwater can be represented in various ways. Plural interests but also plural social values are associated to groundwater. For example, through the analysis of 5 years publications in The Hindu, one of the leading newspapers in India, we identified four typical qualifications of groundwater associated with best management measures: (a) endangered heritage whose access must be regulated, (b) limited resource that must be optimized, (c) issue of survival whose access must be ensured (d) source of emancipation that must be acknowledged (Richard-Ferroudji 2017). The two last ones condone the overexploitation of aquifers. This led us to advocate for a careful consideration of the multiple normative perspective toward groundwater management and emphasizes the importance of compromises between conservation and consumption.

15 The challenge of raising groundwater visibility is shared by many countries. In this project, a comparative stance with India was developed. 
The chapter is organized as follows. Section 1 describes the methodology and introduces the framework used to analyse the communication approaches and tools deployed in each case (public targeted; content, issues brought to the fore and normative stance adopted; type/format). Section 2 develops a transversal analysis of the use of the tools, and identifies assets and limits across the 11 cases. Section 3 discusses the transversal results and concludes with recommendations.

\section{Learning from pioneering experiences}

\subsection{Methodology}

\subsubsection{Eleven cases of policy instruments dedicated to aquifers}

During the past 45 years in France, water policy has evolved from a sector-based and centralized form of management to a more local and integrated one. French water policy promotes tools and procedures that consider hydro-territories ${ }^{16}$ as the relevant areas for integrated management. At a local level SAGEs (local sub-basin plans for water development and management) ${ }^{17}$, contracts (for coordinating agency and other government investment in local public action $)^{18}$ and management structures (which support the making and the implementation of SAGE and contracts $)^{19}$ completed the apparatus. Our study focuses on SAGE and contracts that are dedicated to aquifers. We consider them to be pioneering in making groundwater more visible. Focusing on these cases, we aimed at identifying some original activities and tools to capitalize on the experiences. 11 case studies were selected to illustrate the variety of forms which those initiatives may take (See Table 10.1 and Figure 10.1). They strongly vary in terms of policy instrument (SAGE or contract), management structure (state body, association, etc.), size (from 1 to 10 employees), duration and maturity (one goes as far back as 1954, another one was launched in 2011 ), area (from $346 \mathrm{~km}^{2}$ to $10,138 \mathrm{~km}^{2}$ ) and number of inhabitants $(28,673$ to 1,4 million).

\footnotetext{
${ }^{16}$ Area of land delimited by interdependence to a waterbody (river, lake, wetlands, aquifer, etc.) and draining ultimately to this particular body.

${ }^{17}$ They were founded by the 1992 Water Act to define the management and restoration strategies at the local scale. In 2018, 184 SAGE were implemented, in areas that range from $300 \mathrm{~km}^{2}$ to $10000 \mathrm{~km}^{2}$, more on www.gesteau.fr.

${ }^{18}$ Contract between funders (e.g. a Water Agency, French State, municipalities) instituted by memorandum in 1984 .

19 Territorial bodies tend to associate municipalities at the basin scale in the frame of Syndicat, EPTB or Syndicat Mixte. One should consider that the Water Framework Directive 2000/60/EC strengthened the role of territorial body in water management.
} 


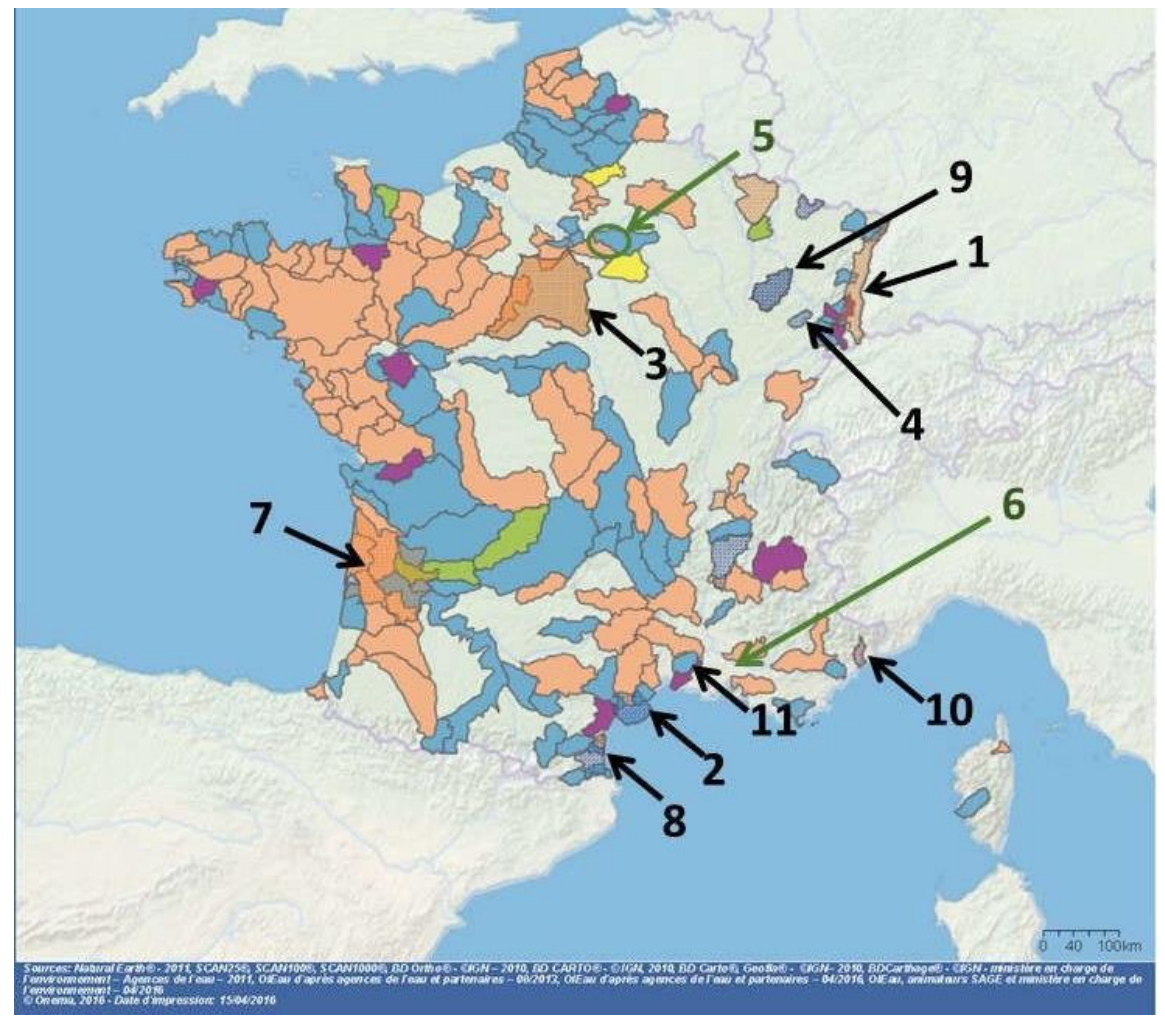

Source of the background map: progress of the SAGE procedures, Gest'eau, www.gesteau.fr, April 15 $5^{\text {th }} 2016$, Yellow: emerging, green and blue: drafting, orange and pink: implementation).

Figure 10. 1: Situation of the 11 cases in France. 
Table 10. 1: Description of the 11 cases (Sources: www.gesteau.fr, June 2016, SAGE documents, contracts, technical reports and interviews).

\begin{tabular}{|c|c|c|c|c|c|c|c|}
\hline $\begin{array}{l}\text { Name of } \\
\text { the aqui- } \\
\text { fer(s) }\end{array}$ & $\begin{array}{c}\text { Manage- } \\
\text { ment struc- } \\
\text { ture }\end{array}$ & $\begin{array}{l}\quad \text { Team } \\
\text { Nbpers. } \\
2016-17 \\
\end{array}$ & Procedure & Starting & $\begin{array}{l}\text { Are } \\
\mathrm{a} . \\
\mathrm{km} 2\end{array}$ & $\begin{array}{r}\text { Nbha } \\
\text { b. (2016) }\end{array}$ & $\begin{array}{c}\mathrm{N} \\
\circ \\
\text { map }\end{array}$ \\
\hline $\begin{array}{l}\text { Ill Rhi- } \\
\text { nAlsace }\end{array}$ & Région & 1 & SAGE & $\begin{array}{r}19541 \text { st man- } \\
\text { agement structure }\end{array}$ & $\begin{array}{l}359 \\
6\end{array}$ & $\begin{array}{l}1,300 \\
000\end{array}$ & 1 \\
\hline Astien & Syndicat & 4 & $\begin{array}{c}\text { SAGE } \\
\text { and contract }\end{array}$ & $\begin{array}{c}1990 \text { syndicat } \\
\text { creation }\end{array}$ & 540 & $\begin{array}{l}110,0 \\
00\end{array}$ & 2 \\
\hline Beauce & Syndicat & 2 & $\begin{array}{c}\text { SAGE } \\
\text { andcontract }\end{array}$ & $\begin{array}{l}\text { 1994charter } \\
\text { on irrigation }\end{array}$ & $\begin{array}{l}950 \\
0\end{array}$ & $\begin{array}{l}1,400 \\
000\end{array}$ & 3 \\
\hline Breuchin & ЕРТВ & $\begin{array}{c}0,6 \\
54 \text { in the } \\
\text { hosting }\end{array}$ & SAGE & $\begin{array}{l}2011 \text { emer- } \\
\text { gence of the } \\
\text { SAGE }\end{array}$ & 380 & $\begin{array}{l}28,67 \\
3\end{array}$ & 4 \\
\hline $\begin{array}{l}\text { Champi- } \\
\text { gny }\end{array}$ & $\begin{array}{l}\text { Associa- } \\
\text { tion }\end{array}$ & 10 & Contract & $1971^{\text {st }}$ contract & $\begin{array}{l}260 \\
0\end{array}$ & $\begin{array}{l}800,0 \\
00\end{array}$ & 5 \\
\hline Crau & Syndicat & 4 & Contract & $\begin{array}{c}2010 \text { emer- } \\
\text { gence of thecon- } \\
\text { tract }\end{array}$ & 550 & $\begin{array}{l}270,0 \\
00\end{array}$ & 6 \\
\hline Gironde & $\begin{array}{l}\text { Syndicat- } \\
\text { mixte }\end{array}$ & 5 & SAGE & 1999 SAGE & $\begin{array}{c}101 \\
38\end{array}$ & $\begin{array}{l}1,400 \\
000\end{array}$ & 7 \\
\hline lon & $\begin{array}{l}\text { Syndicat- } \\
\text { mixte }\end{array}$ & 4 & SAGE & $\begin{array}{r}2003 \text { Frame- } \\
\text { work agreement }\end{array}$ & 900 & $\begin{array}{l}455,0 \\
00\end{array}$ & 8 \\
\hline $\begin{array}{l}\quad \text { Stand } \\
\text { stone of the } \\
\text { earlyTrias- } \\
\text { sic }\end{array}$ & \begin{tabular}{|} 
Departe- \\
mentalCoun- \\
cil
\end{tabular} & 2 & SAGE & $\begin{array}{l}80 \text { 's protec- } \\
\text { tion of Vittel } \\
\text { spring } \\
2000 \text { S } \triangle \text { CE }\end{array}$ & $\begin{array}{l}149 \\
7\end{array}$ & $\begin{array}{l}60,64 \\
2\end{array}$ & 9 \\
\hline \begin{tabular}{|l}
\multicolumn{1}{|c}{ Lower } \\
valley of the \\
Var
\end{tabular} & $\begin{array}{l}\text { Syndicat- } \\
\text { Mixte }\end{array}$ & $\begin{array}{r}2 \text { FTE } \\
20 \text { in the } \\
\text { hosting }\end{array}$ & $\begin{array}{c}\text { SAGE } \\
\text { andcontract }\end{array}$ & $\begin{array}{r}1995 \text { monitor- } \\
\text { ing of the aquifer }\end{array}$ & 346 & $\begin{array}{l}400,0 \\
00\end{array}$ & $0^{1}$ \\
\hline ue Vistrenq & Syndicat & 4 & SAGE & $\begin{array}{c}1986 \\
\text { Syndicat crea- }\end{array}$ & 785 & $\begin{array}{l}250,0 \\
00\end{array}$ & 1 \\
\hline
\end{tabular}




\subsubsection{Inventory and analysis of the uses}

The tools used in each case study were inventoried. The inventory is based on web mining, grey literature review and interviews. We explored (in June 2016) the websites dedicated to groundwater and the management structures of the 11 cases. We used a search engine (Google) to explore the web pages dealing with each aquifer and also the illustrations used on the web. These explorations were completed by research targeted on the use of specific tools in each case, with the following keywords: "scale model", "3D model”, "Facebook", "Twitter ", "film", "video", "game", "exhibition" and "observatory". Besides, more than forty interviews were conducted with transcripts or detailed reports ${ }^{20}$. We first interviewed SAGE facilitators and directors of the management structures. Interviews were then conducted with other stakeholders to gather different points of view (representatives of associations or the administration, elected, teachers, researchers and consultants). Documents (technical studies, guides, reports on school programs, booklets, posters, etc.), web pages, maps, photos, movies and games were collected and analysed. The fact of having 11 cases of study favoured the gathering of a diversity of experience.

\subsection{Framework of analyse}

\subsubsection{Who participates?}

For each tool are identified who promoted them to which audience, and who eventually participated or used it (public engagement). Numerous categorizations are used in the field of water to designate participants. The "Water Parliament" which gives its vote on the SAGE document is for example made up of 3 committees: elected representatives, users representatives (farmers, industrialists, landowners, etc.), and State representatives. With a different perspective, the theory of communication (Shannon-Weaver's model) distinguishes sender and receiver to define a strategy for effective communication through a channel and that can be affected by noise. Communication is then intended as transmitting information to target groups from the general public to specific users. In doing so, it is based on a linear approach to communication. Our approach of communication leads to distinguish participants by their connection to groundwater: their interests, attachments or knowledge. For example, an article in a special issue of the journal Géologues ${ }^{21}$ on Communication and Mediation distinguishes "outsiders" from "insiders" (Marjolet and Normand 2006) ${ }^{22}$. According to these authors, with insiders there is no problem

202 to 5 interviews per case with some collective interviews and some people concerned by several cases (consultant, civil servant).

${ }^{21}$ Geologists in English.

22“"Initiés" vs "non initiés" in the French original version. 
of communication. They share a common scientific or administrative culture and language. The outsiders, by far the most numerous group, are not part of this circle of "common culture" as they use a different idiom and frame problems in a different way $^{23}$. The circle is however a restricted one. It includes, besides experts, some elected representatives, civil servants and members of NGO. Outsiders also include elected officials, civil servants, as well as many members of the civil society. However, lay people may well know the aquifer but not be familiar with the technical language.

\subsubsection{Which issues are made visible and according to what norma- tive stance?}

The following sections examine each tool to identify the issues they tackle regarding groundwater and their normative perspective. Indeed specific issues were at the origin of each SAGE or contract studied, and these may be considered for communication to various interested or affected publics. Issues include groundwater depletion and pollution (e.g. salt intrusion and fluoride), etc. The tools are also underpinned by normative conceptions on groundwater resources management. Many tools promote the principle of resource conservation. However, different objectives can potentially be assigned:

- Develop scientific knowledge and create indicators.

- $\quad$ Make people understand the specificities of groundwater in general or the local resource in particular.

- Change practices: save water, reduce pollution, increase available resources.

- Develop governance and participation of the concerned people

The last objectives focus on the participative nature of the communication tools. Over the last years, participatory groundwater management has been much commented upon but remains a bone of contention between the proponents of expert management and those who advocate the principle of letting water users shape their management institutions (Ostrom 1990). In this regard, special attention should be paid to distinguish participatory tools (Callon et al. 2009).

\subsubsection{Which format of interaction?}

There are different types of communication tools:

- Traditional media (Press, Radio, Television, posters, booklet, mail, etc.).

- Digital media (Online Press, Online advertising, social networks, blogs, groups, forums, websites, emailing, newsletters, MP3, videoconferencing, mobile applications, SMS, shared videos).

\footnotetext{
${ }^{23}$ Marjolet et al. observe during meetings a gap between those who speak of nitrogen and other participants who mention the issue of nitrate which has received much more media attention.
} 
- $\quad$ Events (stands, fair, conferences, etc.).

- Direct contact (in the premises of the structure, by telephone, meeting, training sessions, etc.).

In addition, the given information may be of different formats: texts, numbers, images, diagrams, videos, etc. Special attention will be paid to these different formats across the above four type of tools, as they frame interaction and can affect communication.

\section{A wide range of activities and tools to make groundwater visible}

\subsection{Increase in the available information}

The first result of the study is a strengthening of the visibility of aquifers in the studied cases. We have observed a growing production of information over time ${ }^{24}$ and a gradual widening of the range of tools. Every year new documents are released. Web site or Facebook pages are created. Many documents we examined were intended primarily for specialists, while other communication tools were tailored specifically for awareness campaigns for the lay persons and water users.

Numerous documents are available, not only technical reports for specialists, but also documents for policy makers and the lay public. Booklets and newsletters are produced for a targeted or mass audience. They address a wide range of topics such as wetlands, chlorine pollutions, SAGE procedures, and practical guides to save water or drill borewells. Most of the analysed documents are prepared by the staff of the management structure and technical consultants. Communication consultants are rarely hired. The documents are made available on the internet and distributed during events or through targeted mailing etc. In none of the cases did we identify a systematic mailing to all inhabitants of the groundwater management area, as this is considered too expensive and inefficient.

\subsubsection{Internet used to share information, but rare use of social net- works}

Many documents and related information are made available online in public or private spaces. All the management structures have web pages, either their own website or a webpage hosted by a larger structure. However, the use of the Internet is often limited to information sharing, with little use of the potentialities of this support (interactivity and live communication), with the exception of interactive mapping tools or Facebook pages ${ }^{25}$. Interviewees tend to be sceptical about using

\footnotetext{
${ }^{24}$ Our study provides a benchmark for quantitative evaluation.

${ }^{25}$ In two cases: the Breuchin SAGE and the Crau Aquifer.
} 
social networks. Some people point out that they do not need to communicate quickly on the news. They feel that people are already over solicited and may not be interested in the topic. Others argue in favour of using social networks, recognising that digital media is increasingly used among participants, including elected representatives. However, a lack of time for posting and updating was brought up by all as a critical challenge limiting social media and internet uses.

\subsubsection{Traditional media: visibility in the regional press}

When it comes to traditional media, articles appear in regional and local press, television or radio stations, for example when signing a contract or for a particular event (e.g. a Science Festival). In the national press, the topic is rare, with articles tending to be limited to reporting extreme events (e.g. drought or pollution) or in the case of public controversies (e.g. exploitation by private companies). Groundwater professionals rarely inform the media on a regular basis. Mass communication is perceived as expensive and inefficient. In two cases, however, we noted the use of billboards to promote water savings (Roussillon and Gironde). In such instances of broad dissemination, the campaign benefited from the support of partner organisations (e.g. technical support for the communication services, free access to municipal board journals or district billboards).

\subsection{Toward conventional representations}

\subsubsection{Indicators for information, alerts and regulation}

SAGEs and contracts procedures provide policy settings suited for gathering data on groundwater resources and implementing new studies. These procedures aim at building a common representation of the groundwater systems. In the water field, issues are usually divided into 2 categories: quantitative (related to volume of water) and qualitative (related to water quality). All structures rely on both quantitative and qualitative monitoring networks. Yet, there is still an issue of knowledge development (e.g. on groundwater recharge). Besides, there is less harmonization and formalization of indicators for groundwater than for surface water because groundwater monitoring is younger and the monitoring network less dense (but with territorial variability). Hydrogeology is a relatively young discipline, in which measurement units used for aquifers representation are sometimes yet to be standardized. As a consequence, different indicators for groundwater conditions are in circulation. While an indicator such as the piezometric level is common to all cases, others are more specific (e.g. salinization). The use of these indicators is deeply embedded in the history of local territories. There is a path dependency in the choice of indicator in each case, but to the benefit of adaptation to local issues (e.g. monitoring salinization in the case of coastal Astien Aquifer).

Indicators such as piezometric level are used to objectify groundwater and issues. In all the cases studied, information is conveyed about groundwater levels but 
at different scales (from annual average, monthly measurement, to real-time information). Information is presented with curves, maps or with a clepsydra as an illustration. Groundwater level data is represented with other information such as rainfall or water consumption to understand their dependency. We found that piezometric records are used for different purposes. In some cases, those records were used to inform and/or alert stakeholders about groundwater trends and potential implications for management decision. They are also becoming increasingly instrumental in regulating groundwater uses. SAGE documents can define threshold levels to be used to regulate extraction. The definition of such thresholds is subject to debate and results from negotiations.

Over time, maps and indicators have been refined in terms of spatial and temporal scales. In the cases studied, groundwater professionals now benefit from a range of tools providing shared representations of the local aquifers. In five cases, observatories and dash boards are set up to gather data sets and offer an integrated approach to understanding groundwater conditions. Modelling is also developed to explore management scenarios. Most of the indicators used are biophysical ones. Indicators of socio-economic dimensions are rarely used, with the notable exception of the SAGE of Gironde aquifers which set progress indicators for task completions along with an annual opinion survey entitled "Gironde people and water". Finally, we observed that data production is entrusted to experts and consultants, with rare use of experience with citizens. One rare example of citizen science was found in the Crau case. The managing structure called for volunteers to participate in the monitoring of groundwater levels. This kind of approach has proven to be effective in complementing existing government-run monitoring programs in other regions (Little et al. 2016).

\subsubsection{Maps: essential tools}

All the organisations in our study produce maps and use them in their documents. In SAGE and contracts processes, it is common practice to collect maps in a booklet. Maps are abundant. One interviewee goes as far as to say: "there are never too many maps!" This medium has been used by hydrogeologists since the beginning of the discipline to show these hidden resources while representing their borders at the surface. Today, cartographic methods are used to represent a wide array of topics: aquifer perimeters, piezometric networks or socioeconomic issues (tourism or farming in the area, institutions, etc.). We emphasize the fact that maps can be used to cross aquifers representations with other issues (e.g. groundwater resources and population increase). Maps are produced in different formats and for different audiences. The maps produced in the SAGE documents and in the contracts are mainly intended for "insiders" (elected representatives, NGO representatives, state services officers) and by consulting firms working on groundwater related projects. A certain level of knowledge is required to understand these maps, as well as technical references (e.g. concentration thresholds of pollutants). Many maps are thus difficult to understand by lay people. While considering the purposes for which 
maps are made, all the interviewees recognize the ability of maps to synthesize information and simplify technical aspects. During public hearings, maps are instrumental in fostering discussion with stakeholders. Users confront their own spatial landmarks and their field knowledge with them. Some maps are designed to alert users and convince them to change their practices by highlighting management issues and depletion. We are witnessing the growing use of maps in a regulatory perspective (protection of catchment perimeters, definition of Strategic Zones for drinking water supply or zones vulnerable to nitrates, definition of threshold volumes, etc.). In a few pilot projects, the building of such maps is participatory and proved to be instrumental in involving users to promote common pool resources management. Maps are to play an increasing role in the consultation and the regulation of the uses.

Yet, during interviews, several people also pointed out that map proved at times to be unnecessary or mere decoration. They report low usage and little discussion of SAGE maps that are accepted as technical data. Some deplore the systematic and unavoidable nature of the production of maps without questioning their relevance. Besides, for several respondents, the mapping must remain the responsibility of the expert. In short, although maps appear to be essential to groundwater management, it is necessary to keep a critical stance on their production and uses.

There was consensus among the people interviewed that miniature models are relevant: from the rough (and low cost) ones made by the teams ${ }^{26}$ to detailed representation of the territory and the aquifer (e.g. the upper Rhin Aquifer miniature model).There is a growing use of such models and 3D mapping as this medium can meet a wide array of needs including raising awareness among lay people. 3D makes it possible to represent the superposition of aquifers and to introduce users to the complexity of aquifer dynamics. It is a tool that deploys its potential when used in a digital and interactive form, with the user exploring the $3 \mathrm{D}$ view from multiple angles. The advent of web 2.0 technologies is seen as an opportunity to increase the potential of cartography with interactive mapping platforms. These tools, however, remain difficult to apprehend for people unfamiliar with GIS software. Besides, the cost of 3D technologies or viewers makes this media difficult to access for most organizations. In our study, some of them resented investing in a tool such as 3D modelling that does not necessarily provide added value (compared to maps) to management and collective discussion.

${ }^{26}$ E.g. one crafted with an aquarium, layers of sand and stones, and straws. 


\subsection{The potential of arts, field visits and intermediaries}

\subsubsection{Groundwater is not photogenic but inspires fictions}

We were interested in the use of art and illustrations to make groundwater visible. How can a hidden resource be captured in an image? Illustrations could be photographs, numerical data (tables or graphic illustrations) or drawings ${ }^{27}$. The analysis of the websites showed that photos are barely used. Groundwater is obviously not photogenic, with the exception of some karsts which can be misleading to the public as they represent only one type of aquifers. Groundwater can only be captured in a traditional photographic image in caves or when it gushes from a pipe, percolates on the surface, or lies at the bottom of a well. Stored in sand or pebbles, it is difficult to photograph it. In most cases, groundwater resources are represented by proxies, such as photographs of (A) surface water that interacts with groundwater (tank, lake and river), (B) infrastructures (pumps, motors, pipe) or measurement equipments (piezometers) (C) the users and their practices (a farmer in a field, children drinking, etc.), (D) events concerning groundwater or groundwater professionals (water parliament meeting, exhibition, the team of the management structure), or (E) generic photos on the theme of water (a drop of water, flowing water). Photos may show the social or political dimension of groundwater when capturing groundwater uses or meetings. Some structures have developed photo libraries. This is for example the case of the Symcrau, whose website presents a participatory photo library. Interestingly, the photo library is part of their observatory.

In a number of cases, short documentaries were produced about the local aquifer dynamics and/or its management. Often, these films dealt with water more generally than the specifics of local aquifers. Such videos were considered as necessary for raising awareness by the interviewee, but expensive. They were able to capture the social and political dimensions via people's testimonies. Animated movies were also used to assist peoples' understanding of phenomenon such as groundwater recharge (e.g. in one case, a dinosaur was used to remind the old age of groundwater). Yet, the potential of fictions and the presence of groundwater in culture are underexploited. Feature films and novels are largely untapped formats for increasing the general public's awareness and understanding of groundwater. Interviewees confirm the very low use of fictions, stories or myths despite their relevanceto regain a "culture of water" which is fading. However, some interviewees were wary of fictional material because it may convey and perpetuate misconceptions (according to them) of complex groundwater dynamics and management policy.

From the perspective of visibility and participatory management, it would be interesting to develop the use of popular culture, graphic arts and games. We observed that different structures produced games (e.g. The "game of the camel" on the Astien or the game Gaspido on the Roussillon which are combining goose game, quiz

${ }^{27}$ Cartoons are used in the national press, but not in our cases. 
and challenges) that are used mainly for schools. Drawing from the innovative use of serious games(Meinzen-Dick et al. 2018), this kind of tools can be used to the general public to invigorate awareness campaigns or with insiders to foster collective discussion and explore different scenarios.

\subsubsection{Rallying around aquifers}

Various meetings are organized involving groundwater. The SAGE and the $A q$ uifer contract processes may include meetings of the "Groundwater parliament", of consultative meeting, of thematic groups, of advisory groups (See Chapter 4). Consultation bodies are set up on a permanent or ad hoc basis. Events, conferences and exhibitions are organized to promote a knowledge-awareness and to transmit knowledge to a broad audience whether temporary, travelling or permanent in government or other groundwater manager offices. They are organized by the management structure but more often by partners (e.g. environmentalist associations, Water Agencies, municipalities, universities). Groundwater professionals are invited to share their experience and knowledge.

Our research identified activities dedicated to schoolchildren in all 11 cases. In most of the cases, environmental education associations were mandated by the management structure to implement these activities. Educational activities benefit from funding from French Water Agencies and Ministry of Education. The activities carried out with school children often focus on water saving. They include field trips which play important roles in raising awareness or sharing experiences.

Practitioners also organize field trips for the newcomers in the Water Parliament, to get them acquainted with the issues of the territory. Field trips are activities implemented regularly in some cases but more often once off. They could be further expanded for general public or targeted ones (e.g. bore well owners). Some practitioners shared with us their ideas about how to manifest the physical presence of aquifers at the surface, with boards or art settings as a symbol to represent and map the water under our feet. This is promising area, and would benefit from further exploration to understand how to mark the boundaries and features of groundwater on the surface, so as to raise awareness of its otherwise hidden presence ${ }^{28}$. Yet, faceto-face events and on-the-ground communication (e.g. information stalls, field trips) are still too rarely used. This is because existing management structures lack of investment in staff time and supporting budgets to organize events on a regular basis.

${ }^{28}$ Facing the same issue of oblivion, flood markers remind the possibility of flood. 


\section{Discussion and Conclusion: how to make groundwater more visible?}

\subsection{Diversify the format of communication: from scientific reports to art}

The analysis conducted in the 11 case studies showed that over the last two dec$\operatorname{ades}^{29}$ a variety of communication tools has been developed in the field of groundwater at the local scale. More and more documents are available, mainly for specialists but also for decision makers and the lay public. A lot of information is available online. The potentialities of the digital media could still be developed to favour interaction and participation, but this would require more human resource for facilitation. When it comes to traditional media (e.g. press, TV, etc.), some stories concerning groundwater are covered by the local media but rarely by national ones. Groundwater managers are not inclined to mass communication, which is perceived as costly and inefficient. Their focus is on local appropriation. Documents and websites are illustrated with maps, photographs, numerical data (tables or graphic illustrations) or drawings which represent groundwater. Maps are essential to represent groundwater at the surface. They are abounding. Then a critical stance is needed on their objectives and uses. Maps and indicators have been refined in terms of spatial scale and time scale but also with a legal perspective to regulate the extractions (e.g. "Strategic Resources studies"). They have become conventional representations that support groundwater management and are shared among "observatories". If groundwater is not photogenic, it can be shown indirectly (connected surface water, pumps, pipes, users, etc.) and narrative fiction offers a promising area to share knowledge and explore multiple points of view. Beyond scientific representations, artistic representations deserve to be used to reach a broad audience and represent social and political dimension of groundwater. Moreover, there is potential for development of face-to-face events and field trips as well as landmarks and land art works to materialize the presence of water beneath our feet. Different approaches are required for different publics and to develop capacities, as it is observed in other cases(Re and Misstear 2017). Figure 10. 2 illustrates the diversity and predominance of some tools.

\footnotetext{
${ }^{29}$ Several management structures were created in the 90's and the SAGE were set up in 1992.
} 


\subsection{Foster the unconfining ${ }^{30}$ of groundwater management}

Four types of objectives assigned to the tools that we have inventoried were identified and discussed:

\subsubsection{Develop scientific knowledge and create indicators.}

A first objective is to develop scientific knowledge of the resource and conventional monitoring equipment with a management perspective. This leads to the production and circulation of indicators and maps. This study confirms the hypothesis that nowadays, quantitative issues are more visible than qualitative ones with few exceptions. The quantitative stakes are more emphasized and rely on important equipment from the piezometric maps to "volumetric groundwater management" process. The interviews show that significant investments have been made and are still made in the production of knowledge, which is an important work of visibility. However, efforts are still needed to share this knowledge and to involve people concerned in the production.

\subsubsection{Make people understand the specificities of groundwater in general or the local resource in particular.}

With the former perspective, a second objective assigned to the tools is to make people understand the groundwater systems and issues, raise awareness and capacity. However, we distinguished two approaches. Either communication is about groundwater in general or it insists on the local resource as a common heritage. It is then a matter of developing groundwater knowledge by highlighting local issues and the neighbouring environment related to everyday life and people own experiences.

\subsubsection{Change practices: save water, reduce pollution, increase avail- able resources.}

A third goal is to change practices. Some expected changes are general in the field of water: save water, improve sanitation, reduce the use of pesticides, etc. Other messages are specific to groundwater management: protection of catchments, promoting maintenance of the bore wells and good drilling practices, etc. Even if water mining practices are justified for some people, nowadays, in France, claiming publicly the relevance of groundwater overexploitation can no longer be deemed reasonable. Practically, tools often tackle both this objective and the previous one

${ }^{30}$ If some aquifers are confined, management can also be. Sociology of science distinguishes participatory tools from the ones that are "confined" (Callon et al. 2009) within the restricted spaces of secluded research and representatives designated by ordinary citizens. 
(See Figure 10.2). We distinguished them as this one is oriented toward convincing while the other one is more oriented toward capacity building.

\subsubsection{Develop governance and participation of concerned people.}

The fourth objective focuses on governance. Groundwater related participatory practices are little developed and social mobilization is weak. Studies and data production are entrusted to experts. The lack of resources and the reluctance of technicians or elected representatives are also obstacles to the implementation of participatory approaches. Opponents fear that outsiders would pollute the debate if it is unconfined, while the tenants of participatory approach expect that they will recharge it. Among our pioneering case studies, participatory practices are developing with original initiatives and positive feedbacks (e.g. participatory cartography, citizen science). This fourth objective needs to be fostered.

\subsection{Build on local communities}

As budgets dedicated to communication are limited, there is a tendency for groundwater managers to focus on specific themes and target audiences. The "general public" appears to be a fuzzy notion too difficult to reach. The promoters we interviewed prefer to develop tools targeting specific publics such as tourists or socio-professionals (e.g. farmers or camps managers in the Mediterranean coastal area), municipalities (e.g. Campaign "Stadium without pesticides" on the aquifer of Vistrenque), well owners (e.g. to inform them of good practices in the construction or maintenance of a borewell) or urban planners (e.g. to inform them about water constraints). Communication toward elected representatives is considered as a priority. Meetings, documents or training sessions are specifically tailored for them. However, this public remains heterogeneous, with variable levels of knowledge, involvements and scales of action (from the municipality to the Region). Elected representatives also face a challenging dilemma between territory development and water resources protection. Schoolchildren are considered by interviewees as a multiplier group because they are an investment in the future, as well as transmitters to their family, relatives and neighbours. Initiatives brought to schools are numerous. Yet there is little follow up study of the effectiveness of school education on groundwater. Besides, in the field of groundwater, we found that the associations were mainly involved in an educational perspective with partnership with the management structure. Exceptionally, they are involved as activists and contest projects. Public administration representatives are involved in the SAGE or contract procedures. They are from the sector of water, agriculture or urban planning. It is often a captive public whose participation is linked to their position. The challenge is then to involve them more in local issues. An asset of SAGE and aquifer contracts is their territorial approach. Indeed the objective is not to make groundwater visible but to get people to take care of a specific aquifer that is a common heritage. 


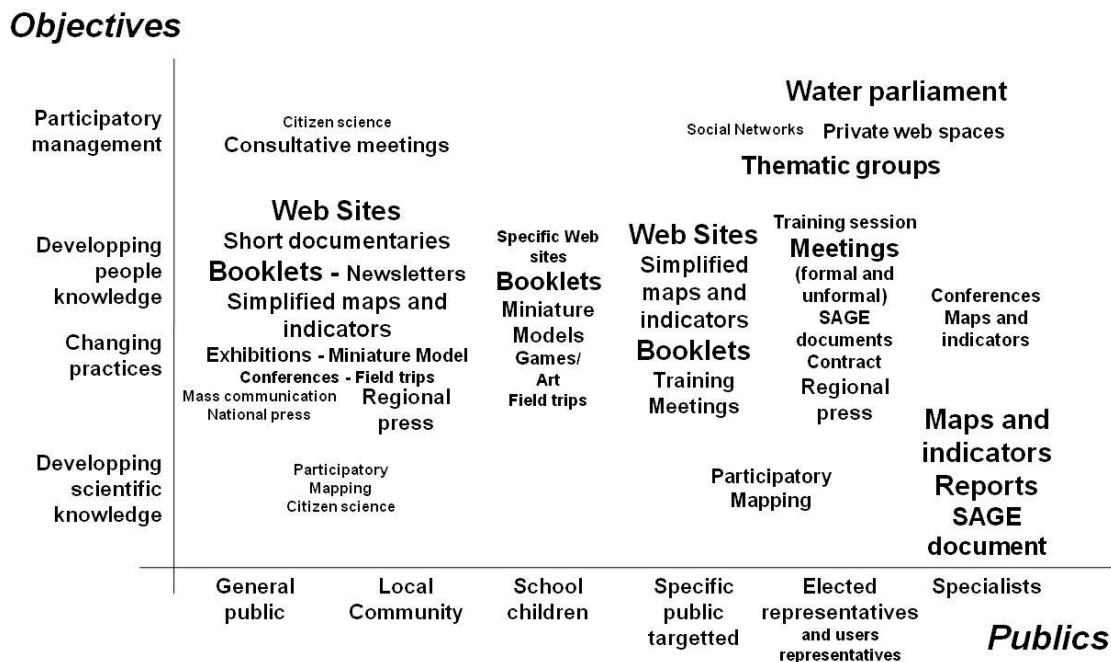

Figure 10. 2: Preferred tools for different objectives and publics with font size representing the extent of their use (the biggest for those used in all the studied cases)

\subsection{Recognize and promote spokespersons for the aquifers}

In France, the employees of management structures play a key role in making groundwater visible. Communication activities often depend on their commitment. Most of them are willing to develop communication. Only one interviewee stated that communication does not relate to his area of work and that groundwater professionals should not venture beyond technical management. They can conceive their role in different ways, from an expert role to that of facilitator, with a dimension of taking care of water bodies and participants such as family doctors (RichardFerroudji 2014). Groundwater professional and specialists dedicate a major part of their time to groundwater. They can be considered as spokespersons for groundwater. This can also be the case of elected representatives, NGO representatives or users which have a thorough knowledge of the subject from different perspectives. Several interviewees also stress the importance of relying on local intermediaries to reach users. In the process, groundwater specialists are asked to expend the gamut of their activities (Lassaube, à par.). While groundwater professionals used to be fo cused on the supply side of groundwater, they now deal with activities meant to curb groundwater uses, ranging from public sensitization to facilitation. Those activities deserve better recognition. Yet, time resources and financial means are missing in most cases. In the management structures, budgets allocated to communication are low. Most of the time, promoters seize opportunities to communicate. In 2 cases only a communication consultant was hired for advice and drafting a communication plan. In order to make groundwater more visible, some support is requested, not only financial but also institutional. Communication activities should 
be better recognised and supported by public funds for livening up groundwater policy.

In short, from this study, we recommend (1) to continue the development of tool with a diversity of formats including artistic ones and field trips, (2) to develop participatory approaches, building on local communities, (3) to recognize and promote spokespersons for the aquifers. Specific budget and public support are needed to create an environment for effective communication and sustainable groundwater management.

\section{Acknowledgements}

This work has been supported by AFB (The French Agency for Biodiversity). The authors would like to thank Bénédicte Augeard, Delphine Loupsans and Claire Magand for stimulating discussions; Xavier Bernard, James Daly and Jeanne Latusek (IFP) for their fruitful contribution to the study; the editors for reviewing the first draft of this chapter and providing valuable comments and all the interviewees who shared their point of view and experiences.

\section{References}

Baldwin C, Tan P-L, White I, Hoverman S, Burry K (2012) How scientific knowledge informs community understanding of groundwater. J Hydrol. doi: 10.1016/j.jhydrol.2012.06.006

Bouarfa S, Kuper M (eds) (2012) Groundwater Governance: Learning from Local Experiences - Irrigation and drainage Volume 61, Issue Supplement S1

Callon M, Lascoumes P, Barthe Y (2009) Acting in an Uncertain World. MIT Press

Curtis A, Mitchell M, Mendham E (2016) Social Science Contributions to Groundwater Governance. In: Jakeman AJ, Barreteau O, Hunt RJ, Rinaudo J-D, Ross A (eds) Integrated Groundwater Management: Concepts, Approaches and Challenges. Springer International Publishing, Cham, pp 477-492

Faysse N, Petit O (2012) Convergent readings of groundwater governance? Engaging exchanges between different research perspectives. Irrig Drain 106-114

Jakeman AJ, Barreteau O, Hunt RJ, Rinaudo J-D, Ross A, Arshad M, Hamilton S (2016) Integrated Groundwater Management: An Overview of Concepts and Challenges. In: Jakeman AJ, Barreteau O, Hunt RJ, Rinaudo J-D, Ross A (eds) Integrated Groundwater Management: Concepts, Approaches and Challenges. Springer International Publishing, Cham, pp 3-20

Lassaube G (A paraitre) Agir en hydrogéologue : étude comparée France/Inde d'une profession en mutation. Thèse de doctorat en sociologie, Université de Bordeaux 
Little KE, Hayashi M, Liang S (2016) Community-Based Groundwater Monitoring Network Using a Citizen-Science Approach. Groundwater 54:317-324

Marjolet G, Normand D (2006) Le Conseil general des Cotes d'Armor: communication et mediation a la Direction $<<$ Agriculture et Environnement $>>$. GeolPARIS- 151:50

Meinzen-Dick R, Janssen MA, Kandikuppa S, Chaturvedi R, Rao K, Theis S (2018) Playing games to save water: Collective action games for groundwater management in Andhra Pradesh, India. World Dev 107:40-53 . doi: https://doi.org/10.1016/j.worlddev.2018.02.006

Mitchell M, Curtis A, Sharp E, Mendham E (2012) Directions for social research to underpin improved groundwater management. J Hydrol 448-449:223-231 . doi: 10.1016/j.jhydrol.2012.04.056

Ostrom E (1990) Governing the commons: the evolutions of institutions for collective action. Cambridge University Press

Re V, Misstear B (2017) How scientific knowledge informs community understanding of groundwater. In: Advances in Groundwater Governance, CRC press. pp $215-230$

Richard-Ferroudji A (2017) Ambivalence des eaux souterraines dans le journal The Hindu: promouvoir leur préservation tout en accueillant des justifications de leur exploitation. Dév Durable Territ Économie Géographie Polit Droit Sociol 8:

Richard-Ferroudji A (2014) Rare birds for fuzzy jobs: A new type of water professional at the watershed scale in France. J Hydrol 519, Part C:2468-2474 . doi: 10.1016/j.jhydrol.2014.09.070

Richard-Ferroudji A, Barreteau O (2012) Assembling different forms of knowledge for participative water management - Insights from the Concert'eau game. In: Claeys C, Jacqué M (eds) Environmental democracy facing uncertainty. Peter Lang, Bruxelles, pp 97-120

Richard-Ferroudji A, Lassaube, Gaia, Bernard, Xavier, Daly, James, Latusek, Jeanne (2018) Mise en visibilité des eaux souterraines et de leurs enjeux de gestionExpériences des syndicats de nappes et structures porteuses de SAGE en France et perspectives indiennes. AFB/CNRS/IFP, Paris

Shah T (2009) Taming the anarchy groundwater governance in South Asia. Routledge, New Delhi

Thévenot L, Moody M, Lafaye C (2000) Forms of valuing nature : arguments and modes of justification in French and American environmental disputes. In: Lamont M, Thévenot L (eds) Rethinking comparative cultural sociology : repertoires of évaluation in France and the United States. Cambridge university press, pp 229272

Van Der Gun J (2017) Data, information, knowledge and diagnostics on groundwater. In: Advances in Groundwater Governance, CRC press. pp 193-214 
Villholth KG, Lopez-Gunn E, Conti K, Garrido A, Van Der Gun J (2017) Advances in Groundwater Governance. CRC Press 